\title{
Development of Local Percentile Growth Charts of Children between Birth to Ten Years
}

\author{
Vikas Chintaman Kakade ${ }^{1}$, Anil Prabhakar Mokashi \\ ${ }^{1}$ Associate Professor, Department of Statistics, Tuljaram Chaturchand College, Baramati-413102, MH, India \\ ${ }^{2}$ Director, Institute of Rural Pediatrics, Bal Kalyan kendra, Baramati-413102, MH, India \\ Corresponding Author: Vikas Chintaman Kakade
}

\begin{abstract}
Growth pattern of human population changes with time and place. Particularly developing countries, country like India, is in a stage of nutritional transition hence it is necessary to update growth references regularly. The present study is carried out on 0-10 years from Baramati from Pune district of Maharashtra. We considered that children from maternity homes, BCG camps, well baby clinics, immunization camps, private clinics, 'Anganwadis and Balwadis', Nurseries' and schools etc. Our study shows that growth performance of Anthropometric indices for Baramati children is much less than National Centre of Health Statistics (NCHS) and slightly less than Indian Council of Medical Research ICMR and Affluent Indians (AI). We have proposed growth charts for Baramati region to monitor growth parameters.
\end{abstract}

Keywords: Anthropometric Indices, NCHS, ICMR, AI.

\section{INTRODUCTION}

Normal growth comprises all dynamic, physiologic and psychological changes which take place from conception to maturity [1]. The term 'growth' has commonly been used for those aspects of maturation which can be described by a measurement of size [2]. The factors nutrition, hormones, secular trends, seasonal, socioeconomic status and other environmental factors play a vital role in growth of an individual [3]. The 'Growth' is measured in specific term like Mean, standard deviations, percentile in the cross sectional studies or longitudinal studies [4] [5].

India is a developing country since under the major nutritional transition stage [6]. In 2006, WHO developed the first single uniform global growth standard as prescriptive chart for the children under the age of 5 years with encouragement to all countries for its applicability [7]. Further WHO stated that it would not be possible to have prescriptive growth standards for children between 5-18 years of age. Since hormonal and environmental factors in this age group cannot be controlled. Nutritional, environmental and genetic factors and timing of puberty play a major role on growth of children above the age of 10 years. Country-to-country and region-toregion variation and impact of these factors on growth, reflects in differing growth patterns amongst different population. Hence, it is necessary to have countryspecific and also region-specific growth charts to monitor growth of children between 5-18 years [8]. Growth charts are most commonly used tools for assessing the health of human population [9], which gives graphical method of comparison of child's growth with reference population of same age and sex. [10]

The factors nutrition, hormones, secular trends, seasonal, socioeconomic status and other environmental factors play a vital role in growth of an individual. In the present state of developmental flux in rural India, growth standards developed on the observed growth performance may be valid 
only for 10 years. The secular trend of gradually increasing height over generations may create the need to re-evaluate growth standards.

\section{Aims and objectives}

The present study was planned with following aims and objectives in mind.

1. To collect suitable data for construction of the reference standards of growth and physical development of children below ten years of age in and around BARAMATI.

2. To assess the extent to which growth performance of Baramati children corresponds to the National Centre of Health Statistics (NCHS) of USA, Indian Council of Medical Research (ICMR) and Affluent Indians (AI) values.

3. To design growth charts for growth monitoring based on Baramati data, improvising upon the available growth charts.

4. To assess the validity of various anthropometric statements used estimation of growth in the field.

\section{MATERIALS AND METHODS}

\section{PROFORMA USED FOR THE STUDY}

Sr. No

Name

Address

Sex

Area

Birth date

Date of examination

Male/Female

Urban/Rural

$\mathrm{DD} / \mathrm{MM} / \mathrm{YY}$

$\mathrm{DD} / \mathrm{MM} / \mathrm{YY}$

Age groups:

\begin{tabular}{|c|c|c|c|c|c|}
\hline 0 $\mathbf{1}$ mth & $\mathbf{2}$ mth & 3 mth & $\mathbf{4}$ mth & 5 mth & 6 mth \\
\hline 7 Mth & 8 Mth & 9 Mth & 10 Mth & 11 Mth & 1.5 Yrs \\
\hline 2 Yrs & 2.5 Yrs & 3.5 Yrs & 4.5 Yrs & 5.5. Yrs & 6.5 Yrs \\
\hline 7.5 Yrs & 8.5 Yrs & 9.5 Yrs & 10 Yrs & & \\
\hline
\end{tabular}

Measurements:

1. Head Circumference

2. Chest Circumference

3. Mid-arm circumference

4. Hand Length

5. Span

6. Height

7. Upper segment

8. Lower segment

9. Foot Length

10. Weight

Name of Examiner

The present cross-sectional study was carried out in and around Baramati, District Pune, Maharashtra. Since the objective of the study was to investigate the growth performance of all the children in and around Baramati below 10 years of age, not subject to any growth restraints.
Hormonal and environmental factors play their role in post pubertal age. So this study was restricted to children below ten years of age. The data is collected from maternity homes, BCG camps, well baby clinics, immunization camps, private clinics, 'Anganwadis and Balwadis', Nurseries' and 
schools. The study team was headed by the research candidate, a pediatrician of 17 years standing and academic credentials. Six part time graduate assistants were employed for period of 2 years. The staff recruited was trained to collect data, record the measurements at Dr. Anil Mokashi Hospital, Baramati and B. J. Medical College, Pune. A statistician was involved from the planning stage of the study and training of the staff. The total number of children investigated in the project was 40200. With such a large coverage in a small community and variety of places of contacts, nearly every eligible child was covered. This totally removed the sampling bias that hampers statistical significance of most of the studies. We measured ten anthropometric indices like the 1)Head Circumference 2)Chest Circumference 3) Mid-arm circumference 4)Hand Length 5)Span 6)Height 7)Upper segment 8)Lower segment 9)Foot Length and 10)Weight for every children.

In this article, we focus only on height and weight of children. The aim of this article is to study of $50^{\text {th }}$ percentile of Baramati. Also, we compare of $50^{\text {th }}$ percentile of Baramati data with ICMR and NCHS data and design a suitable 'Mokashi growth chart' based on Baramati data.

The total number of children covered in the study was 40, 200. Recorded data was classified according to age, sex \& locality. The sex ratio in the study was 1.28 male: 1 female. There were twenty two age groups, out of them first twelve for 12 months and next ten 1-1.5 yr, 1.5- 2yr, ...,9.5-10 yr.

\section{Statistical Methods}

We use the linear regression analysis model at 5 percent level of significance to assess the validity of various anthropometric statements which are used to estimation of growth of anthropometric indices. Descriptive statistics is used to find the mean, S.D. for the anthropometric indices. Also, we use percentiles methods for development of growth charts for of anthropometric indices. Here, we use purposive sampling method to collect the relevant data to achieve the objectives of propose study.

\section{RESULTS}

\section{$50^{\text {th }}$ percentile of anthropometric indices} for height and weight

We obtained $50^{\text {th }}$ percentile of anthropometric indices of height and weight for infants below 1 year and children aged 1 through 10 years using SPSS software. These data have been given in Table 1 to Table 2. In presenting the tables the 'number' given is for the age and the next. For example ' 7 ' includes all children aged ' 7 ' years and above, excluding those who have completed 8 years of age.

Table No. 1: $5^{\text {th }}$ percentile value for Weight in Kg. for infants below 1 year and children aged 1 year through 10 years

\begin{tabular}{|c|c|c|c|c|c|}
\hline \multirow{2}{*}{ Age } & \multicolumn{2}{|c|}{ Weight in Kg. } & \multirow{2}{*}{ Age } & \multicolumn{2}{c|}{ Weight in Kg. } \\
\cline { 2 - 3 } \cline { 5 - 6 } & Boys & Girls & & Boys & Girls \\
\hline 1 Month & 2.8 & 2.65 & 3 & 11 & 10.5 \\
\hline 2 & 4.2 & 3.7 & 3.5 & 12.3 & 11.3 \\
\hline 3 & 5.2 & 4.3 & 4 & 13 & 12 \\
\hline 4 & 5.6 & 5 & 4.5 & 14 & 13 \\
\hline 5 & 5.7 & 5.7 & 5 & 14 & 14 \\
\hline 6 & 6.2 & 6.3 & 5.5 & 15 & 14 \\
\hline 7 & 7.0 & 6.5 & 6 & 15 & 15 \\
\hline 8 & 7.5 & 6.2 & 6.5 & 16 & 15 \\
\hline 9 & 7 & 7.3 & 7 & 17 & 16 \\
\hline 10 & 7.4 & 6 & 7.5 & 17 & 17 \\
\hline 11 & 7.7 & 6.5 & 8 & 18 & 18 \\
\hline 1 Year & 7.8 & 7 & 8.5 & 19 & 19 \\
\hline 1.5 & 8.3 & 8.2 & 9 & 20 & 20 \\
\hline 2 & 9.7 & 8.5 & 9.5 & 20 & 20 \\
\hline 2.5 & 11 & 10 & 10 & 21 & 20 \\
\hline
\end{tabular}

Table No. 2: $50^{\text {th }}$ percentile value of Height in $\mathrm{cm}$. for infants below 1 year and children aged 1 year through 10 years

\begin{tabular}{|c|c|c|c|c|c|}
\hline \multirow{2}{*}{ Age } & \multicolumn{2}{|c|}{ Height in cm. } & \multirow{2}{*}{ Age } & \multicolumn{2}{c|}{ Height in cm. } \\
\cline { 2 - 3 } \cline { 5 - 6 } & Boys & Girls & & Boys & Girls \\
\hline 1 Month & 45 & 45 & 3 & 85 & 84 \\
\hline 2 & 49 & 50 & 3.5 & 89 & 88 \\
\hline 3 & 54 & 51 & 4 & 9613 & 92 \\
\hline 4 & 57 & 57 & 4.5 & 96 & 95 \\
\hline 5 & 59 & 57 & 5 & 100 & 98 \\
\hline 6 & 60 & 62 & 5.5 & 102 & 101 \\
\hline 7 & 63 & 63 & 6 & 105 & 103 \\
\hline 8 & 67 & 62 & 6.5 & 107 & 107 \\
\hline 9 & 65 & 65 & 7 & 111 & 109 \\
\hline 10 & 68 & 65 & 7.5 & 113 & 113 \\
\hline 11 & 69 & 65 & 8 & 116 & 115 \\
\hline 1 Year & 69 & 69 & 8.5 & 118 & 117 \\
\hline 1.5 & 73 & 73 & 9 & 120 & 119 \\
\hline 2 & 77 & 74 & 9.5 & 121 & 121 \\
\hline 2.5 & 82 & 81 & 10 & 123 & 123 \\
\hline
\end{tabular}

From Table-1 the observations were made that birth weight boys and girls are 2.8 $\mathrm{kg}$ and $2.65 \mathrm{~kg}\left(50^{\text {th }}\right.$ percentile $)$ respectively. 
Weight gain in 10 years for boys and girls are $18.2 \mathrm{~kg}$ and $18.1 \mathrm{~kg}\left(50^{\text {th }}\right.$ percentile $)$ respectively. Also, from Table-2 the observations were made that birth height boys and girls are $45 \mathrm{~cm}\left(50^{\text {th }}\right.$ percentile $)$. Height gain in 10 years for boys and girls are $78 \mathrm{~cm}\left(50^{\text {th }}\right.$ percentile $)$.

\section{DISCUSSION}

There is no point in shouting loudly 'we don't have Indian Reference Standards to assess our children's growth'. There is also no point in evaluating how much percentage of NCHS or Boston standard our children compare with. Growth norms are not 'sacred' like national anthem! It is not a matter of national pride! To have growth standards is a scientific need.

Our Job is to see that our children grow well in existing socioeconomic and hereditary scenario. We have to identify and correct the growth derivations as early as possible. We need something to compare with that is 'applicable', 'scientific', 'standardised' and 'handy'.

Under the circumstances we logically pursue the hypothesis that a growth standard in a community should be based on the growth performance of all the 'normal children'. Selecting only affluent children is as good as using NCHS data. It is well established that the most important two growth promoting factors are 1) Growth monitoring 2) Proper nutrition.

All the other factors play a minor role. Growth monitoring and nutrition depend upon Knowledge, attitudes, customs, beliefs and practices. Those who know, about diet and growth monitoring, have well fed well grown children. Those who do not know have smaller size children. Growth is not an Urban/Rural, Rich/Poor, North/South or East/West problem. Growth is a knowledge/Lack of knowledge problem. 1] At the beginning of the study we thought Urban/Rural differences may not be significant. We decided to put forward the hypothesis that "Rural children are not lagging behind the Urban children in growth! "But the study revealed that in fact rural children were really lagging behind. Our presumption proved to be wrong and more emotionally based in favour of 'our rural' and those urban'. So we dropped the hypothesis!

2] In the present state of developmental flux in rural India, growth standards developed on the observed growth performance may be valid only for 10 years. The secular trend of gradually increasing height over generations may create the need to re-evaluate growth standards. Our study shows that growth performance of Baramati children is much less than NCHS and slightly less than ICMR and AI. So there is no case for the NCHS standard to be used as a yardstick to assess Indian children.

3] $50^{\text {th }}$ percentile of Baramati data is presented in tabular format for each measurement viz. Head, Chest, Mid arm circumference, span, hand length, foot length, weight, height and upper segment and lower segment. The $50^{\text {th }}$ percentile figures for boys and girls are depicted separately for each criterion. The $50^{\text {th }}$ percentile figures for Baramati data generally match with ICMR data and are overall slightly on lower side of ICMR. These are ready for use as a cut off line for field conditions.

4] Comparison of Baramati data with other studies:

All the indices in Baramati data were matched with NCHS/ICMR data. The NCHS figures in all measurements were higher than ICMR and Baramati data. Baramati data matched with $30^{\text {th }}$ percentile of NCHS. The ICMR figures were generally above Baramati data; still they were closely matching (insignificant statistical difference) barring a few differences.

a) Growth of Baramati children lagged behind Indian and International levels between 6 months to 1 year of age: Probably because of delayed weaning and lack of growth monitoring.

b) Chest circumference overtakes Head circumference by about two years of age [8]. It is supposed to be an 'Health Indicator'. In case of Baramati children this 
occurred at 4 years. Probably indicating 'not so healthy' state of affairs.

5] Mokashi Growth Chart:

The 'road to health chart' gives a wrong impression of minimum and maximum growth. In fact the lower line $\left(50^{\text {th }}\right.$ percentile ICMR) is not a minimum, and upper line $\left(50^{\text {th }}\right.$ percentile NCHS) is not a maximum. It is a drawback of the road to Health Chart.

The rainbow chart has too many lines, curves, figures on it. It is incomprehensible for paramedical workers (who are untrained) and mothers.
The growth chart was designed with above problems in mind. The Baramati data of 40200 children was subjected to analysis for percentiles. The curves for $3^{\text {rd }}, 50^{\text {th }}$, and $97^{\text {th }}$ percentile were plotted. The age groups 0-1 years and 1-10 years are depicted on separate charts. Presence of 3(two prominent and one dotted) curves removes the minimum-maximum concept and avoids the confusion of many curves. The message that a given child should follow his own path is enough and easily understood. The chart is presented as follows:
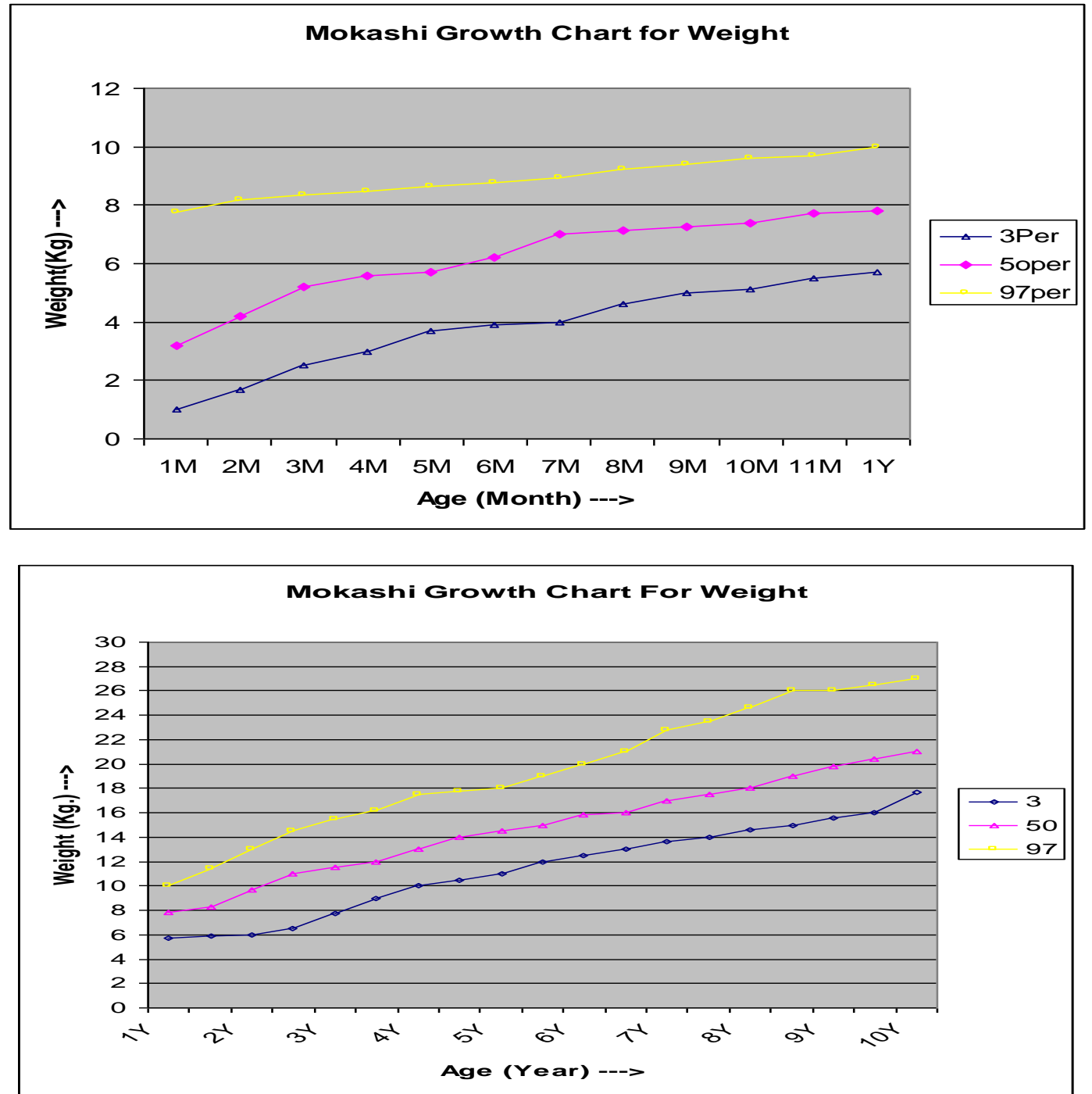

\section{Infant growth:}

The growth of an infant since birth shows a regular increase in all the anthropometric measurements. In this study, this was indicated by the increase in both percentile values of the measurements. The girls were shorter and lighter than the boys. Boy had a broader chest and larger head circumference. 

years

The standard deviations appeared to increase with age and these were lower in infants than in children aged 1 to 10 years for all measurements except head circumference and upper segment. The measurements appeared to be more compact in later months of infancy than in earlier months as compared by the co-efficient of variation.
It was interesting to note that, on an average, the growth of infants during the first 6 months after birth was more rapid as compared with their growth in the later months.

The statement made for longitudinal growth estimation was not included as this study was a cross-sectional one.

\begin{tabular}{|c|l|c|}
\hline No & \multicolumn{1}{|c|}{ STATEMENT } & TRUE / FALSE \\
\hline 1 & Weight in kg after 1 yr = (Age in Yrs+3) x 2 & FALSE \\
\hline 2 & Height in inches = Age in Years x 2.5+30 & FALSE \\
\hline 3 & Weight in kg up 1 Yr= (Age in months/2) +3.5 & TRUE \\
\hline 4 & $\begin{array}{l}\text { Weight in kg between 1 to 5 Yrs = }(\text { Age in Yrs+3)x2 } \\
\text { Based on the study) }\end{array}$ & $\begin{array}{l}\text { TRUE } \\
\text { Weight in kg between 5 to 10 Yrs = (Age in Yrs+2)x2 }\end{array}$ \\
\hline 5 & At birth head is larger than chest by $3 \mathrm{~cm}$ & TRUE \\
\hline 7 & At birth span is less than length by $1-2 \mathrm{cms}$. & TRUE \\
\hline
\end{tabular}

\section{CONCLUSIONS}

Our study proposes the new anthropometric statements for estimation of growth in the weight of children for Baramati rural area. Also, the innovative outcome of this study is the common mother can assess the growth of her children using Mokashi Growth chart.

\section{Acknowledgement: None}

\section{Conflict of Interest: None}

\section{Source of Funding: None}

\section{REFERENCES}

1. P.N. Wahi, ICMR studies on growth and physical development of Indian infants and children, Scientific report, 1966

2. Chai O. P., Sandhu R. K., Study of physical growth in Indian Children in Delhi, Indian J. Pediatrics. 1968; 85:91

3. Dattabanik N. D., Semi longitudinal growth evaluation of children from birth to 14 years in different socioeconomic groups. Indian Pediatrics, 1982;19;353

4. Agarwal DK, Agarwal KN, Upadhyay SK, Mittal R, Prakash R, Rai S. Physical and sexual growth pattern of affluent Indian children from 5-18 years of age. Indian Pediatr 1992;29:1203-82.

5. Agarwal D.K., Agarwal K.N. Physical growth in Indian afflyent children ( Birth to years) Indian Pediatrics, 1994;31:377-412.

6. Kuczmarski RJ, Ogden CL, Guo SS, Grummer-Strawn LM, Flegal KM, Mei Z, et al. 2000 CDC Growth Charts for the United States: Methods and development. Vital Health Stat 2002;246:1-190.

7. RK Marwaha, N Tandon, MA Ganie, R Kanwar, Shivaprasad c, ASamharwal, K Bhadra, A Narang. Nationwide reference data for height, weight and body mass index of Indian schoolchildren. The national med. Jour of India 2011;24:5

8. Rao S. Nutritional status of the Indian population. J Biosci 2001; 26: 481-489.

9. WHO Child Growth Standards. Acta Pediatr Supplement. 2006;450:5-101.

How to cite this article: Kakade VC, Mokashi AP. Development of local percentile growth charts of children between birth to ten years. International Journal of Research and Review. 2021; 8(11): 26-31. DOI: https://doi.org/10. 52403/ijrr.20211105 